\title{
Examination of the Effectiveness of Sternberg's Successful Intelligence Program on Executive Functions of Sharp-Witted Primary School Level Students
}

\author{
Mokhtar Malekpour ${ }^{1}$, Mozhgan Shooshtari ${ }^{2}$, Ahmad Abedi $^{1} \&$ Amir Ghamarani ${ }^{1}$ \\ ${ }^{1}$ Faculty of Psychology and Educational Sciences, Department of Psychology and Education of Children with \\ Special Needs, University of Isfahan, Iran \\ ${ }^{2} \mathrm{PhD}$ student of Psychology and Education of Children with Special Needs Faculty of Psychology and \\ Educational Sciences, University of Isfahan, Iran \\ Correspondence: Mokhtar Malekpour, Faculty of Psychology and Educational Sciences, Department of \\ Psychology and Education of Children with Special Needs, University of Isfahan, Iran. E-mail: \\ mokhtarmalekpour@ymail.com
}

Received: March 15, 2016

Accepted: April 4, 2016

Online Published: June 8, 2016

doi:10.5539/mas.v10n8p75

URL: http://dx.doi.org/10.5539/mas.v10n8p75

\begin{abstract}
The current research aimed to investigate the effectiveness of Sternberg's successful intelligence program on executive functions of sharp-witted primary school level students. The statistical universe of the current research consisted of all male sharp-witted students of the city of Isfahan in the educational year of 2015-2016. For this purpose, the number of 30 male sharp-witted students was selected through multi stage cluster random sampling method and was randomly placed in two experimental and control groups (15 people in the experiment group and another 15 in the control group) and their mothers, too responded to the questions of the executive skills scale. The Sternberg's successful intelligence program was administered on the experimental group. The tool used for this research included a questionnaire (inventory) on rating executive functions for the primary school level students (parent form). To analyze the research data, multivariate covariance analysis (MANCOVA) was applied. Findings revealed that training of the Sternberg's successful intelligence program was effective on executive functions (response inhibition, active memory, emotional control, focus attention, assignment initiation, planning, organizing, time leadership, goal-orientedness, resilience and metacognition) of sharp-witted children. The Sternberg's successful intelligence program could be applied as an intervention method for improving executive functions of children.
\end{abstract}

Keywords: sternberg's successful intelligence program, executive functions, sharp-witted, primary schools

\section{Introduction}

From among factors that could significantly contribute to the educational performance of students are cognitive abilities and executive functions. In other words, whenever students possess optimal cognitive abilities and good executive functions, they will have more success in acquiring skills and special content based knowledge (Best,2010).During the last decade, much attention was paid to the role of executive functions during childhood and it has been stated on the same basis that proper development and training of executive functions contributes mainly to the social development, academic and school achievement of children (Hart et al. 2010). Executive skills are among abilities which are needed by children for learning at schools (Coleman et al., 2006).

Executive skills adjust outputs of behavior and usually include inhibition and control of stimuli, working memory, cognitive resilience, planning and organizing (Hughes and Graham, 2002). In other words, executive skills are a set of higher abilities involving self-autonomy, self-initiation, planning, cognitive resilience, working memory, organizing, dynamic perception of the time, prediction of the future and problem solving which help children in daily activities and learning assignments and tasks (Dawson and Guare, 2004). Generally, most researchers have accepted that executive skills are self-regulating skills which demonstrate the child's ability for inhibition, self-regulation, planning, organizing, use of working memory, problem solving and goal-setting for performing textbooks assignments (Pennington, 2008; Willcutt et al.2010). 
According to Vohs and Baumeister (2014), three kinds of abilities constitute the basis and foundation of executive functions and they are: inhibition, working memory and cognitive resilience. However, some experts have divided these main skills into more detailed skills like attention inhibition and action inhibition, verbal or visual-spatial working memory, self-regulation, goal-setting, planning and problem solving (Ebrahimi et al. 2013). These functions are also closely related with mechanisms of control and following goals which modify and navigate main elements of different cognitive processes (Micco et al. 2009). Executive functions are major structures which play the fundamental role in controlling and navigating behavior and are of significance for adaptation and performance in actual life. These functions allow people to initiate and complete their tasks and resist against challenges, discern unexpected situations and design programs and schemes in proportion to situations, manage daily stresses and refrain from conducting inappropriate conducts (Zeid Abadi Nezhad et al.2013).The term executive functions refers to a whole involving various functions like decision making, planning, inhibition and organizing which require higher cognitive skills like attention, active memory, language, perception and creative thinking. These functions help people with performing learning assignments, intelligence actions and educational issues (Aminaee and Moosavi Nasab, 2014; Firoozi et al. 2011).

Also, neurocognitive executive functions are neurocognitive goal-oriented processes which are responsible for controlling and coordinating behavior and are related with psychological processes responsible for controlling consciousness, thinking and function. In the Barclay's paradigm, executive functions are defined as: self-controlling acts applied for self-autonomy (Garner, 2009). Generally, executive functions could include attention to concentrated information and concentration on it and inhibition from irrelevant information (attention and inhibition), change of focus and concentration on assignments (assignment management), sequential planning for doing assignments for meeting goals (planning), updating and investigation of the content of active memory for determining later steps in chain assignments (review) and representation of codes in the active memory (encoding) (Anderson et al. 2001; Swanson et al.2010).

These functions include integration of multifaceted sensory data, creation of various responses, maintenance of the set, purposeful behaviors, adaptation with environmental changes, the ability for planning and self-assessment (Blair et al. 2005). Executive functions also refer to a set of cognitive processes which are applied in managing purposeful behavior (Locascio et al. 2010). Executive functions involve the highest cognitive performances which are necessary for purposeful behavior (Thorell et al.2009; Best and Miller, 2010; Dehn, 2008). Thus, one of the concerns in the area of education in the current century is the quality of educating learners who possess desirable cognitive abilities and appropriate executive functions. Also, a number of studies affirm that the active memory capacity could increase along with training in this memory (Comblain, 1994; Mc Namara and Scott, 2001; Minear and Shah, 2006; Clingberg et al., 2005). In fact, via training in the active memory, one can stimulate areas in the brain being related with this memory (Takeuchi et al., 2010). Thus, given the significance of executive functions and the issue of cognitive abilities and the active memory of children, today, numerous ways such as movement based and rhythmic games (Dehghani et al., 2012), self-regulation training (Beiramil, 2012), training of movement-mental skills (Zeid Abadi Nezhad et al., 2013), cognitive rehabilitation (2012), psychological-educational interventions (2010), movement actives (Best, 2010) could be used for empowering children in this area. One of the programs whose effectiveness can be examined on executive functions and cognitive abilities is Sternberg's successful intelligence program. One of the most recent projects raised recently is the Sternberg's successful intelligence program. This successful intelligence program which was introduced following the introduction of successful theory by Sternberg became operational in 2007 by Sternberg and Grigorenko and taught by theorists in educational courses to children.

This theory states successful people have three analytical creative and practical abilities that could be taught to children. Successful intelligence is a set of integrated abilities which are necessary for success in life; however, the individual determines it in his own social and cultural context. People who determine their own strong points and use them more, while at the same time they determine their own weak points and seek ways for correcting or compensating them are successfully intelligent people. Successfully intelligent people via using a balance between analytical, creative and practical abilities adapt to the environment and form them and choose (Sternberg, 2010). Successful intelligence theory is one of the effective and comprehensive theories in the area of intelligence and intelligence assessment which has applied various perspectives and views. It is considered as a modern theory, does not emphasize on psychometric principles and is theorized based on empirical accomplishments, theoretical studies, psychological progress in computer and development of the approach of news dissemination.

Sternberg argued that which introduces intelligence is not the IQ, rather intelligent behaviors are thought of accurate introducer of intelligence abilities. He maintains that the nature of intelligence is highly complicated 
and one cannot determine all constructive dimensions of intelligence through paper-pencil tests. According to this theory, being intelligent is something more than studying lessons and an intelligent person is an individual who knows how to apply his own intelligence under different situations (Sternberg, 2009). He is concerned with analysis and explanation of processes as to see how and with what mechanisms people resolve subjective assignments and issues, how they promote skills related with thinking and reasoning and expose better performance in dealing with various issues (Sternberg, 2007; Negahban Eslami et al., 2014). Major elements which constitute the basis of successful intelligence program are as follow (Sternberg et al., 2011; Sak, 2007):

The ability to attain success in accordance with personal standards in the heart of social cultural context of the person;

The ability of the individual to acquire success hinging on utilizing strong points and reform or making up his own weaknesses;

Successful intelligent people are successfully intelligent;

To adapt with the environment, forming and choosing them requires a skill based balance;

Implicit knowledge and wisdom are cornerstone of practical intelligence;

Success is made via certain balance among three dimensions of intelligence; analytical, creative and practical.

The individual has to constantly analyze situations in life, make use of internal sources creatively and adapt to new work. People who are successfully intelligent show balance in these three kinds of abilities of thinking. Therefore, given the threefold thinking ability of analytical, creative and practical (three abilities which make up for successful intelligence are analytical ability, creative ability and practical ability) they become successful. Analysis ability is used when the person performs analysis, assessment and comparison. Creative ability is used when the person creates, invents and discovers. Practical ability is applied when the individual performs that which he has learned (Sternberg, 2008). Successful intelligent people show some kind of balance in these three abilities. At school, the kind of thinking which is expected from students is that of analytical. However, outside of school and in the real world, creative thinking ability and particularly practical thinking ability may assume more importance (Sternberg et al. 2011, Sak, 2007). As regards why successful intelligence engenders in improved performance of students compared to traditional methods even in remembrance and memory tests, Sternberg (2008) states that there are at least four reasons for this. Firstly, teaching by way of successful intelligence method results in encouragement of more detailed and extended decoding of material in comparison to more traditional methods. Hence, students will favorably be able to remember material at the time of taking exams. In addition to this, education according to the above method results in decoding of information in various forms such that more grounds will be provided for remembering information at the time of examinations. Thirdly, this method results in placement of emphasis on strong points and compensation of weak points. Fourthly, this teaching method is more motivating for students and teachers, because it engenders inmore learning for students and more effective teaching for teachers. In another research on curriculum of reading done by Sternberg et al. 2011; Grigorenko, Jarvin, Sternberg, 2003, reading was overtly taught at the junior school level by way of successful intelligence; however at the high school level, it was mixed with mathematics, sciences, social sciences, English, History, foreign languages and arts. Under all these conditions, students who were subjected to education by way of three-fold methods managed to outperform students who had been taught through traditional methods. Thus, given the researches done and above-mentioned material the main research question is formulated as: Does the Sternberg's successful intelligence program affect executive functions of sharp-witted primary school level students?

\section{Methodology}

Since the main goal of the research is to investigate the effectiveness of the Sternberg's successful intelligence program on executive functions of sharp-witted primary school level students, the methodology is an experimental study with a clinical experimentation which is performed with pretest and posttest along with control group. In this research, the Sternberg's successful intelligence program is considered independent variable and executive functions are regarded as dependent variable while gender is considered control variable. 
Table 1. Diagram of pretest-posttest with control group

\begin{tabular}{|c|c|c|c|c|c|c|}
\hline Group & $\begin{array}{l}\text { Random } \\
\text { of subjects }\end{array}$ & selection & Pretest & $\begin{array}{l}\text { Independent } \\
\text { variable }\end{array}$ & Posttest & Interventions \\
\hline $\begin{array}{l}\text { Experimental } \\
\text { group }\end{array}$ & & $\mathrm{R}$ & $\mathrm{T} 1$ & $\mathrm{X} 1$ & $\mathrm{X} 2$ & $\begin{array}{l}\text { Sternberg's successful } \\
\text { intelligence program }\end{array}$ \\
\hline Control group & $\mathrm{R}$ & & $\mathrm{T} 2$ & - & $\mathrm{X} 2$ & Control \\
\hline
\end{tabular}

\subsection{Statistical Population, Sampling and Sampling Method}

The statistical population of the current research consists of all boy sharp-witted students in the city of Isfahan in the educational year of 2015-2016. The research sample includes 30 students who have an IQ rate of over 120 who were selected through cluster sampling method. The sampling was as follow: from among 4 educational districts in Isfahan, two districts were randomly selected and from among sharp-witted schools of these two districts, five classes were selected randomly and from these five classes, 30 students were randomly chosen. Both experimental and control groups were given 15 students each. It is noteworthy that the sample volume in experimental researches for each subgroup is 15 people (Cohen et al. 2007). Mothers of both groups were administered a pretest and then, the experimental group was placed under the Sternberg's successful intelligence program for 11 sessions of two hours each while the control group did not receive any such intervention and after that mothers of both groups were administered a posttest.

Table 2. Explanation of Sternberg's successful intelligence program sessions

\begin{tabular}{|c|c|}
\hline Sessions & Content \\
\hline First session & $\begin{array}{l}\text { Familiarity of students with each other-giving pretest, explanation of the Sternberg's } \\
\text { successful intelligence program (analytical, creative and practical intelligence) }\end{array}$ \\
\hline Second session & $\begin{array}{l}\text { Administration of creative intelligence program (completion of incomplete } \\
\text { stories-talking of objects-talking of animals) }\end{array}$ \\
\hline Third session & $\begin{array}{l}\text { Administration of creative intelligence program (talking of numbers-application of } \\
\text { unusual objects-non-structural games) }\end{array}$ \\
\hline Fourth session & $\begin{array}{l}\text { Administration of creative intelligence program (unusual paintings and extension of } \\
\text { forms, etc.) }\end{array}$ \\
\hline Fifth session & $\begin{array}{l}\text { Administration of practical intelligence program (placement of students in various } \\
\text { situations and request for decision making and explanation about various solutions } \\
\text { for solving problem) }\end{array}$ \\
\hline Sixth session & $\begin{array}{l}\text { Administration of practical intelligence program (education of making up a tool like } \\
\text { an metallic thing, education of using an ATM) }\end{array}$ \\
\hline Seventh session & $\begin{array}{l}\text { Administration of practical intelligence (education of using the library- education of } \\
\text { making up wallpaper, etc.) }\end{array}$ \\
\hline Eighth session & Continuation of the seventh session \\
\hline Ninth session & $\begin{array}{l}\text { Administration of analytical intelligence program (ability to find rational links } \\
\text { between numbers, between forms-creation of opportunity for improving the abstract } \\
\text { ability of students-filling in of empty spaces via considering relationship between } \\
\text { others) }\end{array}$ \\
\hline Tenth session & $\begin{array}{l}\text { Continuation of the sixth session-review of programs taught and response to } \\
\text { students'questions }\end{array}$ \\
\hline Eleventh session & Review of educated programs- appreciation of students' participation-giving posttest \\
\hline
\end{tabular}

\subsection{Research Tools}

Primary school level students' executive functions Scale-Parent form: Executive skills scale (Dawson and Guare, 2008) has been constructed for measuring executive functions of children. This scale contains 33 items. The subject is asked to specify his executive skills in 11 areas of (response inhibition, active memory, emotional control, focus attention, assignment initiation, planning, organizing, time leadership, goal-orientedness, resilience and metacognition). In each part of the eleven areas, the subject is demanded to rate a range of each items held true about them on a Likert scale ( $5=$ totally agree, $4=$ agree, $3=$ no idea, $2=$ disagree, $1=$ totally disagree). In the study by Dawson and Guare (2008), the reliability of this scale in a group of 168 children was $0 / 81$ and the 
reliability coefficients of its subscales by way of retest after five weeks were as reported in the following Table and via factorial analysis, the above eleven factorial loads were obtained.

Table 3. Reliabilitty of executive skills of ESS-P scale

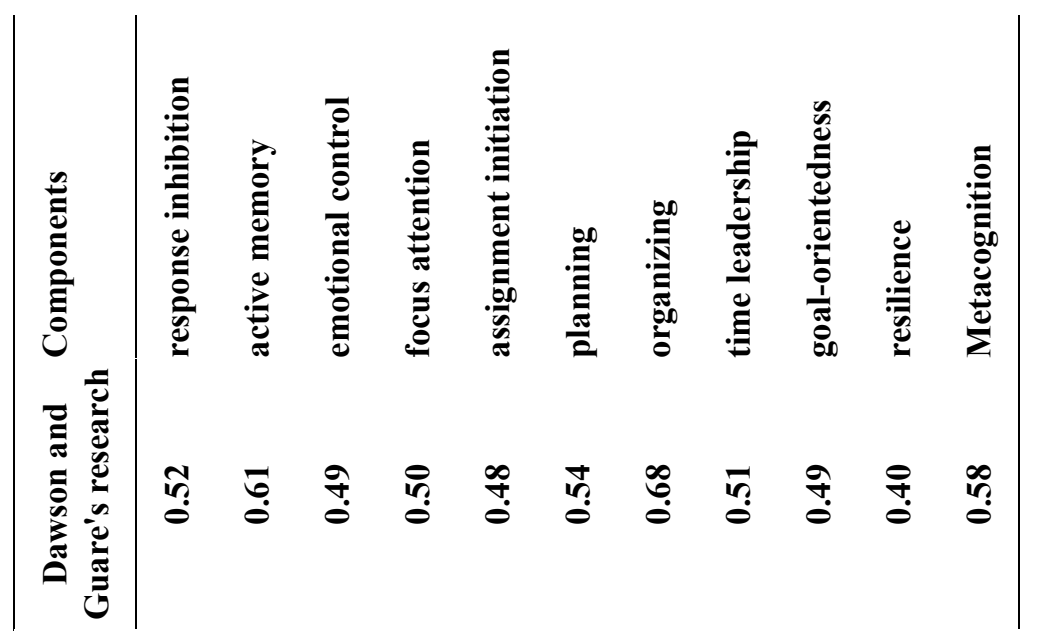

\section{Findings}

Table 4. Mean and standard deviation of executive functions of children in pretest and posttest as distinguished by groups

\begin{tabular}{lllllllll}
\hline \multirow{2}{*}{ Variable } & \multicolumn{3}{l}{ Experimental group } & \multicolumn{4}{l}{ Control group } \\
\cline { 2 - 9 } & Pretest & \multicolumn{3}{l}{ Posttest } & Pretest & \multicolumn{3}{l}{ Posttest } \\
\cline { 2 - 9 } & $\mathrm{M}$ & $\mathrm{SD}$ & $\mathrm{M}$ & $\mathrm{SD}$ & $\mathrm{M}$ & $\mathrm{SD}$ & $\mathrm{M}$ & $\mathrm{SD}$ \\
\hline Response inhibition & $5 / 27$ & $1 / 668$ & $8 / 67$ & $2 / 350$ & $6 / 20$ & $1 / 781$ & $6 / 67$ & $1 / 543$ \\
Active memory & $5 / 73$ & $1 / 792$ & $8 / 20$ & $2 / 274$ & $5 / 67$ & $1 / 877$ & $6 / 27$ & $1 / 580$ \\
Emotional control & $7 / 07$ & $1 / 163$ & $9 / 13$ & $1 / 727$ & $7 / 13$ & $1 / 246$ & $7 / 47$ & $1 / 407$ \\
Focus attention & $7 / 60$ & $1 / 246$ & $9 / 87$ & $1 / 846$ & $7 / 33$ & $1 / 234$ & $7 / 80$ & $1 / 740$ \\
Initiation of activity & $5 / 47$ & $0 / 915$ & $8 / 27$ & $2 / 219$ & $5 / 87$ & $0 / 990$ & $6 / 07$ & $1 / 280$ \\
Planning & $6 / 87$ & $1 / 506$ & $8 / 93$ & $1 / 831$ & $6 / 73$ & $1 / 280$ & $7 / 00$ & $1 / 604$ \\
Organizing & $5 / 67$ & $1 / 175$ & $8 / 60$ & $1 / 805$ & $5 / 80$ & $1 / 612$ & $6 / 53$ & $1 / 767$ \\
Time leadership & $5 / 40$ & $0 / 910$ & $9 / 40$ & $2 / 261$ & $6 / 13$ & $1 / 302$ & $6 / 60$ & $1 / 549$ \\
Goal-orientedness & $7 / 53$ & $1 / 246$ & $9 / 13$ & $1 / 767$ & $7 / 20$ & $1 / 373$ & $7 / 33$ & $1 / 345$ \\
Resilience & $7 / 67$ & $1 / 447$ & $9 / 33$ & $2 / 350$ & $7 / 13$ & $1 / 457$ & $7 / 20$ & $1 / 568$ \\
Metacognition & $7 / 40$ & $1 / 352$ & $9 / 87$ & $2 / 295$ & $7 / 73$ & $1 / 163$ & $8 / 13$ & $0 / 915$ \\
Total score of & $71 / 67$ & $4 / 186$ & $99 / 40$ & $8 / 854$ & $72 / 93$ & $6 / 628$ & $77 / 07$ & $6 / 170$ \\
executive functions & & & & & & & & \\
\hline
\end{tabular}

Since there are one independent variable and several dependent variables and because the effects of the pretest have been modified, the statistical test of Multivariate covariance analysis (MANCOVA) was applied. The research variables being natural was affirmed by the Kolmogorov-Smirnov test $(p<0.05)$. The Box's test also affirmed the homogeneity assumption of Covariance-Variance ( $p<0.62$ and Box $M=11 / 62)$. In order to observe assumption of homogeneity of variances, the Leven's test was used where the estimated significance level in all subscales of executive functions was greater than 0.05 ; i.e. homogeneity assumption of variances was satisfied. Therefore, one can use Multivariate covariance analysis (MANCOVA). 
Table 5. Overall results of multivariate variance analysis in the posttest of executive functions

\begin{tabular}{llllll}
\hline Test name & Value & Assumption freedom degree & Error freedom degree & F statistic & P \\
\hline Pillai's effect & $0 / 758$ & 11 & 18 & $5 / 137$ & $<0 / 001$ \\
Wilks' lambda & $0 / 242$ & 11 & 18 & $5 / 137$ & $<0 / 001$ \\
Hetling's effect & $3 / 139$ & 11 & 18 & $5 / 137$ & $<0 / 001$ \\
Roy's greatest root & $3 / 139$ & 11 & 18 & $5 / 137$ & $<0 / 001$ \\
\hline
\end{tabular}

As seen in Table 5, in the two experimental and control groups, Pillai's effect, Wilks' lambda ,Hetling's effect and Roy's greatest root were estimated so that it is determined whether the Sternberg's successful intelligence program is effective on primary level sharp-witted children's executive functions or not. Results of fourfold tests suggested that control and experimental groups have a significance t difference with eachother in one of the variables $(\mathrm{p}<0 / 001)$. In order find out the fact which one of the executive functions of the sharp-witted primary school level students has been significantly affected by the Sternberg's successful intelligence program, the MANCOVA statistical test was applied where the results are provide in Table 6.

Table 6. Distinguished results of multivariate covariance test in posttest scores of executive functions

\begin{tabular}{|c|c|c|c|c|c|c|c|}
\hline \multicolumn{2}{|c|}{ Dependent variables } & SS & Df & MM & $\mathrm{F}$ & $\mathrm{P}$ & Eta \\
\hline \multirow{10}{*}{ 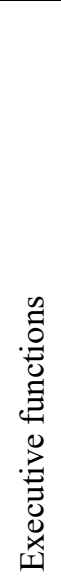 } & Response inhibition & $30 / 025$ & 1 & $30 / 025$ & $7 / 590$ & $0 / 010$ & $0 / 213$ \\
\hline & Active memory & $28 / 033$ & 1 & $28 / 033$ & $7 / 313$ & $0 / 012$ & $0 / 207$ \\
\hline & Emotional control & $20 / 833$ & 1 & $20 / 833$ & $8 / 394$ & $0 / 007$ & $0 / 213$ \\
\hline & Focus attention & $32 / 033$ & 1 & $32 / 033$ & 9/951 & $0 / 004$ & $0 / 264$ \\
\hline & Initiation of activity & $36 / 300$ & 1 & $36 / 300$ & $11 / 064$ & $0 / 002$ & $0 / 264$ \\
\hline & Planning & $28 / 033$ & 1 & $28 / 033$ & $9 / 465$ & $0 / 005$ & $0 / 253$ \\
\hline & Organizing & $32 / 033$ & 1 & $32 / 033$ & $10 / 040$ & $0 / 004$ & $0 / 264$ \\
\hline & Time leadership & $58 / 800$ & 1 & $58 / 800$ & $15 / 650$ & $0 / 001$ & $0 / 359$ \\
\hline & Goal-orientedness & $24 / 300$ & 1 & $24 / 300$ & $9 / 851$ & $0 / 004$ & $0 / 260$ \\
\hline & Resilience & $34 / 133$ & 1 & $34 / 133$ & $8 / 554$ & $0 / 007$ & $0 / 234$ \\
\hline & Metacognition & $22 / 533$ & 1 & $22 / 533$ & $7 / 382$ & $0 / 011$ & $0 / 209$ \\
\hline
\end{tabular}

In this analysis, the pretest variable has been modified due to correlation with the posttest. In accordance with Table 3, the group has had a significant effect on posttest scores $(p<0 / 001)$ and Eta square in each of the variables of response inhibition, active memory, emotional control, focus attention, assignment initiation, planning, organizing, time leadership goal-orientedness, resilience and metacognition out of executive functions among sharp-witted primary level children at 0/213,0/264,0/264,0/253,0/264,0/359,0/260,0/234 and 0/209 respectively indicates changes resulting from the impacts of the Sternberg's successful intelligence program ion executive functions of primary school level students.

\section{Conclusion and Discussion}

Neurocognitive executive functions are neurocognitive goal-oriented processes which are responsible for controlling and coordinating behavior and are related with psychological processes responsible for controlling consciousness, thinking and function. In the Barclay's paradigm, executive functions are defined as: self-controlling acts applied for self-autonomy (Barkley, 1997). From another perspective, response inhibition of executive functions could be considered as an index for performing behavioral performances with two criteria of when and how which help ordinary people to have appropriate and reflective behaviors (Loftiz, 2009) and pave the way for planning of goals, self-autonomy, response inhibition, appropriate assistance, resilience and future-centered behavior (Garner, 2009). Studies have demonstrated that executive dysfunctions may culminate in destructive impacts on daily activities of people like the ability to work and focus at schools and in assessment situations, independent and free performance at expansion and maintenance of social relations and creation of appropriate affective and emotional behaviors (Watkins et al. 2005).

Thus, the current research aimed to investigate the effectiveness of Sternberg's successful intelligence program 
on executive functions of sharp-witted primary school level students. The research indicated that the Sternberg's successful intelligence program is effective on executive functions including response inhibition, active memory, emotional control, focus attention, assignment initiation, planning, organizing, time leadership, goal-orientedness, resilience and metacognition of sharp-witted children. Though no study was ever found to have exactly investigated the subject of the current research, studies by Comblain (1994), Mc Namara and Scot (2001), Minear and Shah (2006) and Takeuchi et al. (2010) implicated that via training, one can enhance the active memory and the activity of that part of the brain which is related with the brain and thus strengthen executive functions among children. In other words, executive skills are a set of higher abilities involving self-autonomy., self-initiation, planning, cognitive resilience, working memory, organizing, dynamic perception of the time, prediction of the future and problem solving which help children in daily activities and learning assignments and tasks (Zalazo et al. 2003).

Some children are weaker than other students in terms of functions of inhibition, decision making, planning and organizing. Generally, executive functions could include attention to concentrated information and concentration on it and inhibition from irrelevant information (attention and inhibition), change of focus and concentration in assignments (assignment management), sequential planning for doing assignments for meeting goals (planning), updating and investigating the content of active memory for determining later steps in chain assignments (review) and representation of codes in the active memory (encoding) (Anderson et al. 2001; Swanson et al.2010). These functions include integration of multifaceted sensory data, creation of various responses, maintenance of the set, purposeful behaviors, adaptation with environmental changes, the ability for planning and self-assessment (Blair et al. 2005). Executive functions also refer to a set of cognitive processes which re applied in managing purposeful behavior (Locascio et al. 2010). Executive functions involve the highest cognitive performances which are necessary for purposeful behavior (Thorell et al.2009; Best and Miller, 2010; Dehn, 2008). Also, there is evidence of researches indicating expansion of executive functions from childhood to adulthood which implicate at the age range of 7-10, growth of executive functions is rapid and by the end of adulthood, this growth rate reaches its peak; this finding mentions the necessity of training executive functions from childhood to adulthood (Locascio et al. 2010).

To explain the subject, one can state that improved executive functions depend to a large extent on child's experiences and the training of the Sternberg's successful intelligence program which places emphasis on analytical, practical and creative intelligence has managed to increase this organizing and increase executive functions of primary school level children via providing an opportunity for enriching sharp-witted children's educational setting; because people of successful intelligence show a balance in these three kinds of thinking.At school, the kind of thinking which is expected from students is that of analytical. However, outside of school and in the real world, creative thinking ability and particularly practical thinking ability may assume more importance (Sternberg et al. 2011, Sak, 2007).Also, in a research conducted on kindergarten children, it was concluded that training working memory would improve general abilities of students in the end of first year and could leave positive effect in the executive functions of these students; thus it can said that working memory has direct effects on the working memory (Best, 2010).

This research was faced with some limitations like failure to use a follow up test for accurate determination of peoples' status being subjected to long term interventions, age limitations of the subjects and small sample size; thus it is advised to examine the effectiveness of a large spectrum of this program in different groups of children and in different time intervals. Another limitation of this research is that, the fact the subject under study is new, little literature review, particularly in the area of Persian Literature was provided with regard to the Sternberg's successful intelligence program. Also, since this program and its education was time consuming and the process of research was administered at school, it was impossible to increase the number of sessions and examination of more dependent variables was tricky and out of the time limits.

\section{References}

Aminaee, F., Moosavi, N., \& Seyed, M. H. (2014). On the comparison of executive functions of students affected with dyslexia with ordinary students. Quarterly of Latest from Cognitive Sciences, 16(3), 53-60.

Anderson, V. A., Anderson, P., Norttam, E., Jacobs, R., \& Catroppa, C. (2001). Developmental of executive functions through late childhood and adolescencein an Australian sample. Developmental Neuropsychology, 20,385-406.

Beirami, M. (2012). Effectiveness of self-regulation training on executivefunctions and reading performance of dyslexic students. Psychological Modern Research Quarterly, 29(8), 48-71.

Best, J. R. (2010). Effects of physical activity on children's executive function: Contributions of experimental 
research on aerobic exercise. Developmental Review, 30, 331-351.

Best, J. R., \& Miller, P. A. (2010). Developmental perspective on executive function. Child Developmental, 81, 1641-60.

Blair, C., Zelazo, P. D., \& Greenberg, M. T. (2005). The measurement of executive function in erlychildhood. Journal of Developmental Neurpsychology, 28, 561-71.

Cohen, L., Manion, L., \& Morrison, K. (2007). Research Methods in Education (6 th ed). London: RoutledgeFalmer.

Coleman, M. R., Buysse, V., \& Neitzel, J. (2006). Recognition and response: An early Intervetion system for young children atrisk for learning disabilities.Full report. Chapel Hill: The University of North Carollina Frank Porter Graham Child Development Institute.

Comblain, A. (1994). Working memory in Down's syndrome: Training the rehearsal strategy. Down Syndrome: Research and Practice, 2, 123-126.

Daneman, M., \& Carpenter, P. A. (1980).Individual differences in working memory and reading. Journal of Verbal Learning and Verbal Behavior, 19, 450-466.

Dawson, P., \& Guare, R. (2004). Executive skills in children and adolescents: A practical guide To assessment and intervention.New York: Guilford Press.

Dawson, P., \& Guare, R. (2008). Executive skills Approach to Helping Kids Reach Their Potential.Guilford Press.

Dehghani, M., Karimi, N., Taghi, P. J. A., Hasan, N. J. F., \& Zeid, A. F. (2012). Effectiveness of movement and rhythmic games on executive functions of children affected with learning neurocognitive disabilities in the primary school level. Learning Disabilities Journal, 2(1), 53-77.

Dehn, M. J. (2008). Working memory and academic learning. Wiley, 123-135.

Jaeggi, S. M., Buschkuehl, M., Jonides, J., \& Perrig, W. J. (2008). Improving fluid intelligence with training on working memory. Proceedings of the National Academy of Sciences, 105(19), 6829-6833.

Ebrahimi, A. A., Abedi, A., Faramarzi, S., \& Behrooz, M. (2012). Executivefunctions among children and adolescents: manual of measurement and intervention, by Dawson and Richard Guare, Isfahan, Neveshte publication.

Ebrahimi, A. A., Abedi, A., \& Shirani, M. (2014). Examining psychometric features of executive functions scale for primary school level children (parent form). Educational measurement quarterly, 15(5), 60-76.

Firoozi, S., Ebrahimi, G., \& Dor Taj, Fariborz (2011). On the comparison of executive functions based on test anxiety among fifth grade students. Research in Applied Psychology, 12(1), 76-85.

Garner, J. (2009). Conceptualizing the relations between executive functions and self_regulatedlearning. Journal of Psychology, 143, 405-426.

Grigorenko, E. L., Jarvin, L., \& Sternberg, R. J. (2002). School-based tests of the triarchic theory of intelligence: Three settings, three samples, three syllabi. Contemporary Educational Psychology, 27, 167-208.

Hughes, C., \& Graham, A. (2002). Measuring executive functions in childhood: Problems and Solutions? Child and Adolescent Mental Health, 7(3), 131-42.

Hart, T., \& Jacobs, H. (2010). Rehabilitation and management of behavioral disturbances lobe injury. Journal of Head Reha, 8, 1-12.

Klingberg, T., Fernell, E., Olesen, P. J., Johnson, M., Gustafsson, P., Dahlstrm, K., Gillberg, C. G., Forssberg, H., \& Westerberg, H. (2005). Computerized training of working memory in children with ADHD: a randomized, controlled trial. Journal of the American Academy of Child and Adolescent Psychiatry, 44, 177-186.

Locascio, G., Mahone, E. M., Eason, S. H., \& Cutting, L. E. (2010). Executive dysfunction among Children with reading Comprehension deficits. Journal of Learning Disabilities, 6, 1-14.

Loftiz, W. C. (2009). An ecological validity study of executive function measures in children with And without attention deficit hyperactivity disorder. Journal of Learning Disabilities, 34, 237-248.

McNamara, D. S., \& Scott, J. L. (2001).Working memory capacity and strategy use. Memory \& Cognition, 29, $10-17$.

Micco, J., Henin, A., Biederman, J., Petty, C., \& Berker, D. (2009). Executive function in patients with 
depression and anxiety. Journal of Depress Anxiety, 26, 78-79.

Minear, M., \& Shah, P. (2006). Sources of working memory deficits in children and possibilities for remediation. In S. J. Pickering (Ed.), Working memory and education (pp. 273-307). Burlington, MA: Academic Press.

Narimani, M., \& Soleimani, E. (2013). Effectivenessof cognitive rehabilitation on executive functions (working memory and attention), and academic achievement of students affected with learning disability in mathematics. Learning disabilities journal, 2(3), 91-115

Negahban, E., Mahmood, F., Valy, A., \& Sarami, G. R. (2014), Examining factorial structyure, validity and reliability of the successful intelligence questionnaire. Educational measurement quarterly, 15(5), 114.

Pennington, B. F. (2008). Toward a new neuropsychological model of attentiondeficit Hyperactivity disorder: Subtypes and multiple deficits. Biological Psychiatry, 57, 211-223.

Sak, U. (2007). Giftedness and the Turkish culture. In S. N. Phillipson \& M. McCann (Eds.), Conceptions.

Sternberg, R. J. (2007). Finding students who are wise, practical, and creative. Chronicle of Higher Education, 53(44), B11.

Sternberg, R. J. (2008). The WICS approach to leadership: Stories of leadership and the structures and processes that support them. Leadership Quarterly, 19(3), 360-371.

Sternberg, R. J. (2009). Reflections on ethical leadership. In D. Ambrose \& T. L. Cross (Eds.), Morality, ethics and gifted minds. New York: Springer.

Sternberg, R. J. (2010). College admissions for the 21st century.Cambridge, MA: Harvard University Press.

Sternberg, R. J., \& Grigorenko, E. L. (2007). Teaching for successful intelligence (2nd ed.). Thousand Oaks, CA: Corwin.

Sternberg, R. J., Jarvin, L., \& Grigorenko, E. L. (2011). Explorations in giftedness.New York: cambridge university press.

Swanson, H. L., Kehler, P., \& Jerman, O. (2010). Working memory, strategy knowledge, and strategy instruction in children with reading disabilities. Journal of Learning Disabilities, 43(1), 24-47.

Takeuchi, H., Sekiguchi, A., Taki, Y., Yokoyama, S., Yomogida, Y., Komuro, N., Yamanouchi, T., Suzuki, S., \& Kawashima, R. (2010). Training of working memory impacts structural connectivity. Journal of Neuroscience, 30(9), 3297-3303.

Thorell, L. B., Lindqvist, S., Nutly, S. B., Bohlin, G., \& Klinberg, T. (2009). Training and Transfer effect of executive function in preschool children. Journal of developmental sciences, 2, 106-130.

Vohs, K. D., \& Baumeister, R. F. (2004). Understanding self-regulation: An introduction.

Watkins, L., Robbins, T., \& Veale, A. (2005). Executive function in obsessive compulsive. Journal of Brain and Cognition, 43, 98-120.

Willcutt, E. G., Doyle, A. E., Nigg, J. T., Faraone, S. V., \& Pennington, B. F. (2010). Validity of The executive function theory of attentiondeficit/ hyperactivity disorder: A metaanalytic Review. Biological Psychiatry, 57, 1336-1346.

Zeid, A. N., Fateme, M. P., Mokhtar, F. S., Choopan, Z., Taghi, P. J., \& Abbas, A. (2013). Effectiveness so mental-movement training on executivefunctions of primary schoollevelaffected with non-verbal learning disabilities. Cognitive Sciences Quarterly, 15(3), 33-39.

\section{Copyrights}

Copyright for this article is retained by the author(s), with first publication rights granted to the journal.

This is an open-access article distributed under the terms and conditions of the Creative Commons Attribution license (http://creativecommons.org/licenses/by/3.0/). 